\title{
FORUM
}

\section{A Further Note on Seaborne Traffic}

\author{
from Capitaine de Frégate L. Oudet
}

I. The channel Bridge. I am happy to report that Commandant Poll's admirable scheme for traffic in the Strait of Dover (p. 75) has provoked, at least on paper, a most interesting reaction. Commandant Poll brought out his plan in February 1960. In March the Compagnie Française d'Entreprises consulted me about a scheme for a Channel Bridge which they had drawn up in conjunction with the English firm of Dorman Long and the American MerritChapman and Scott Company.

As seamen we hold no brief either for a bridge or for a tunnel; our personal interest can be no more than an expression of our attitude as citizens of our respective countries. But as soon as the matter was brought to my attention I realized that there can be no two opinions about our professional attitude: we must first make sure that the bridge will neither endanger nor delay shipping, and when we are satisfied on that point, we must do nothing to hinder the realization of a project which cannot fail to improve international relations in our ageing West.

How are we to make sure of our necessary condition? The first and most important step is to establish the one-way routes detailed by Commandant Poll, and to see to it that the arches which cross them are as wide as possible. The normal span, 200 metres from pier to pier, with a clearance of 53 metres, is suitable only for small ships. For larger ships, 600 metres, with a clearance of 70 metres, may not be too much.

How many arches should we allow for ? Let us assume, to simplify matters, that the traffic amounts to rooo ships, and that a span of 600 metres allows the passage of 100 ships travelling in the same direction. For each direction of traffic, then, we need:

I arch on the English coast route

3 arches on the central route

I arch for the French coast route

-a total, that is, of ten 600-metre arches.

This, no doubt, is a very high estimate, and we could at a pinch make do with narrower arches, and even cut down their number. At the same time I am quite sure that there should be no stinting - see how wide a berth is given to any hazard by a liner or a tanker and you will realize that they will not be completely happy even with a margin of 600 metres.

We must recognize, too, that the broad indication of the various routes will not in itself ensure a smooth flow of traffic; they will need navigational aidsbuoys, radio indication of direction-to give extreme navigational precision in approaching the bridge.

Finally, ships often arrive in groups, and allowance must therefore be made for some mechanism to control and eventually govern their movements. 
One way and another, a considerable organization will have to be set up; the technical difficulties, however, are by no means too great-after all, many large ports have installations hardly less elaborate than those the bridge will call for.

2. The crossings of traffic streams. It appears, accordingly, that the organization of the Straits traffic in three main streams will not only improve the present situation but may also, if need be, satisfy more extensive requirements in the future. As far as our prime interest goes, it has the immediate advantage of rendering unnecessary what I have previously described as the Goodwins roundabout. The roundabout was not a satisfactory solution to the problem of the crossing of routes, but the problem still remains; and the recent London Conference reopened it by bringing up at the International Convention on the Safety of Life at Sea the idea of convergence-zones.

How do we define these? A convergence-zone is one in which there is a junction of maritime routes, clear of a prominent danger spot which they all have to negotiate. Fig. I represents diagrammatically a complete convergencezone, with the routes fanning out on either side of the danger points $D$, and the

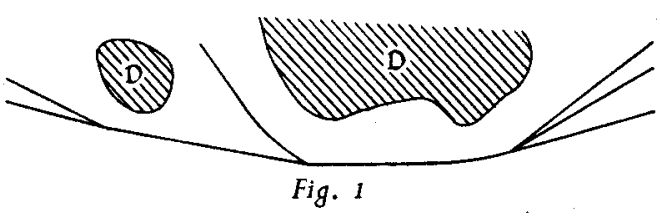
route which clears them-the route determined by the blue lines. What we now have to consider is the spread of the fans, which brings out the complex pattern of convergence and divergence of routes.

When I suggested the roundabout as a way of allowing the simultaneous division of traffic between five routes, I made the mistake of trying to solve too many problems at the same time. The right way, as Commandant Poll has shown, is the cartesian method of breaking down one complex problem into a number of simple problems.

If we approach it from this angle, we soon see that a complex zone such as that in Fig. I may be reduced to a number of more elementary convergences (Fig. 2), and it is this latter that we must now examine as a problem of maritime traffic. In other words, how can we assist the application of the Regulations to the groupings of ships collected on routes $\mathrm{B}$ and $\mathrm{C}$ which unite to form route $A$ ?

Meeting-risks fall under three heads :

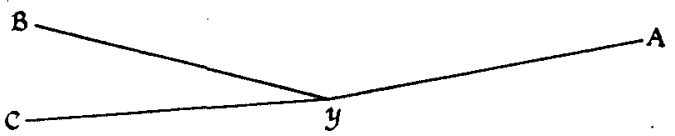

When there is divergence between $\mathrm{AB}$ and $\mathrm{AC}$.

When there is convergence between $\mathrm{BA}$ and CA.

When there is crossing of $A C$ and $B A$.

When the convergence-zone is not determined-as at present it never isthe three risks can exist simultaneously over the whole of an indefinite area on either side of the point $Y$. The very extent of the area means that dangerous crossings are comparatively rare; but from time to time there may be a concentration of three or more mutually obstructive ships, and the result is a collision.

Now, if all the ships are spread out along the blue lines, we reduce the width of the convergence-zone at each end of the lines, and we thus increase the collision-risk in those zones. An answer must be found to this difficulty. 
The first remedy that occurs to one is to extend the blue lines so that they include the whole of the convergence-zone. In this way the three types of encounter are kept separate (Fig. 3).

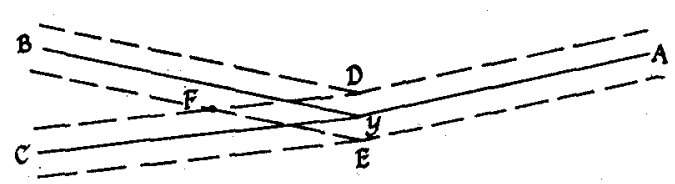

Fig. 3

$D$ is the point of convergence $E$ is the point of divergence $F$ is the area of crossing.

At any one moment, no ship has more than one type of risk to worry about, and manceuvre is already greatly simplified.

Such a solution, effected by marking the blue lines on charts, would probably be sufficient in most convergence-zones; but there remain some where there is so exceptional a concentration of traffic and so high a collisionrate that extra precautions against the most dangerous type of encounter, crossings, will be called for.

The technique we recommend in such cases is shown in Fig. 4. In the area MXNY, traffic b2 manœuvres, on the approach of $\mathrm{c}_{2}$, to join the latter; crossing - $\mathrm{cI}_{\mathrm{I}} \mathrm{b}_{2}$ - should be effected outside this area; divergence- $\mathrm{CI}_{-}-\mathrm{bI}_{\mathrm{I}}-\mathrm{can}$ be effected without difficulty before reaching point $\mathrm{N}$. As soon as c I traffic has passed $\mathrm{N}$, it makes a bold alteration to cross the $\mathrm{b}_{2}$ traffic somewhere within the parallelogram NXQP and follows route $C$ when it has crossed the line $X Q$.

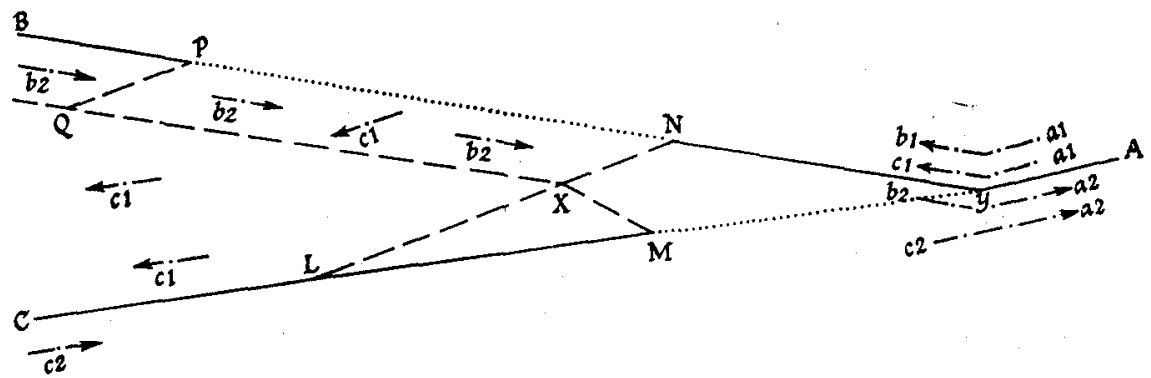

Fig. 4

Note that normally no traffic makes use of the triangle LMX; it would be well to buoy this area, somewhere about point $\mathrm{X}$, to allow accurate navigation.

Such is the recommended procedure, particularly off Beachy Head, where collisions are as numerous as in the Strait proper. Blue lines are marked well out to sea from Beachy Head in order to avoid the dangerous and useless confusion of the English coastal traffic with the main stream; similarly in the neighbourhood of Dungeness, to keep the London traffic separate from the North Sea traffic.

Finally, at the south-western end of the route which runs south of the Colbart, traffic should normally be light enough to call for no more, in the convergence zone, than the blue lines for Vergoyer-Casquets and Vergoyer-Lizard. 